\title{
The ADAPAR Birth Cohort Study: Food Allergy Results at Five Years and New Insights
}

\author{
Dilek Doğruel Gülbin Bingöl Mustafa Yılmaz Derya Ufuk Altıntaş \\ Department of Pediatric Allergy and Immunology, Çukurova University Faculty of Medicine, Adana, Turkey
}

\section{Key Words}

Allergic diseases · Birth cohort · Food allergy · Tolerance

\begin{abstract}
Background: Although food allergy (FA) is often a transient condition during childhood, when and in whom FA will resolve can be affected by many factors. In this study, we analyzed the data at 5 years on 33 children diagnosed with FA in the ADAPAR (Adana Pediatric Allergy Research) birth cohort study in southern Turkey. Methods: Thirty-three infants detected as having FA at the end of their first year in the ADAPAR study were assessed every 6 months until the age of 5 years. Each follow-up included a clinical examination, questionnaire, blood sampling and a skin-prick test. Results: Culprit allergens were cow's milk $(n=20)$, eggs $(n=17)$, chicken meat $(n=1)$ and bananas $(n=1)$. Of the 17 patients with egg allergy, 14 developed complete tolerance and 1 developed partial tolerance (i.e. tolerance to baked food). Of the 20 patients with milk allergy, complete tolerance was observed in 16 and partial tolerance in 1 . The mean age of tolerance to egg was $22.4 \pm 7.5$ months and to cow's milk, it was $20.9 \pm 1.1$ months. Complete tolerance developed in 1 case allergic to chicken meat and in 1 case allergic to banana. Other allergic conditions were also determined: allergic rhinitis in $27.2 \%$, atopic dermatitis in $21.2 \%$, asthma in $9 \%$, urticaria in $9 \%$ and drugs in $9 \%$. Conclusions: Our results confirm ear-
\end{abstract}

\section{KARGER}

E-Mail karger@karger.com

www.karger.com/iaa ly and high tolerance rates before school age in children with food allergies that started in infancy. This will help pediatricians to give more informed advice to parents of infants with cow's milk or hen's egg allergy.

(c) 2016 S. Karger AG, Basel

\section{Introduction}

Food allergy (FA) generally has a good prognosis and is expected to resolve in the majority of children by school age. In several studies, varying results regarding FA tolerance development rates and timing have been reported [1]. In the recent EuroPrevall birth cohort studies, a good prognosis was reported at an early age [2,3]. Such studies allow the understanding of the development and natural history of the disease via a longitudinal approach. Understanding the natural history of food allergies is an important task for preventing the development of other allergic diseases. Additionally, prospective population-based studies are required to identify risk factors for the persistence of FA and other allergic diseases $[4,5]$. To date, no birth cohort study on the prognosis of FA and allergic diseases had been undertaken in Turkey. The primary aim of this prospective cohort study was to describe the rates of resolution in this group of patients and investigate the natural course of FA from infancy to childhood.
(C) 2016 S. Karger AG, Basel

$1018-2438 / 16 / 1691-0057 \$ 39.50 / 0$ 


\section{Material and Methods}

\section{Study Design and Setting}

From February 2010 to February 2011, a total of 1,475 infants born at Çukurova University Medical Hospital, Adana, Turkey, were recruited to participate in the longitudinal ADAPAR (Adana Pediatric Allergy Research) birth cohort study. The aim of the ADAPAR study was to establish the prevalence of atopic dermatitis (AD) and identify associated risk factors by following infants in the city of Adana (southeast Turkey) from birth until 1 year of age. The study has been described in detail elsewhere [6]. Study protocol was approved by the University's Human Research Ethics Committee. Written informed consent was obtained from the parents of each participating infant at enrollment and again at each follow-up.

\section{Follow-Up Assessment}

Thirty three infants who were detected as having FA at the end of their first year in the birth cohort study were assessed every 6 months until the age of 5 years. Each follow-up included a clinical examination, questionnaire, blood sampling and a skin-prick test (SPT). The questionnaire included information on asthma, allergic rhinitis and $\mathrm{AD}$ with validated questions from the International Study of Asthma and Allergies in Childhood questionnaire and adverse reactions to other foods [7]. Specific $\operatorname{IgE}$ (sIgE) against the 6 most common food allergens was analyzed using an Immuno$\mathrm{CAP}^{\circledR}$ kit. If the test was positive $(\geq 0.35 \mathrm{kU} / \mathrm{l})$, then the serum was analyzed for sIgE antibodies to cow's milk, hen's eggs, soy, wheat, fish and peanuts. An SPT test was performed using commercially available extracts of the major inhalant allergens (Allergopharma, Germany), tree mixture, mold mixture, pollen mixture, Dermatophagoides pteronyssinus and D. farinea, and the food allergens, cow's milk, eggs, wheat, peanuts, bananas and fish. The results were considered positive if the mean wheal diameter was $\geq 3 \mathrm{~mm}$ compared to the negative control. In addition, SPT and sIgE level measurements were carried out when there was any suspicion of FA according to history and/or physical examination.

Drug allergy was suspected in children who had a history of any reaction after a specific drug intake; it was confirmed by measuring drug-specific IgE and/or SPT and/or a drug provocation test [8]. The diagnosis of FA in children with a history of symptoms associated with specific food intake and/or those with food $\operatorname{sIgE} \geq 0.35$ $\mathrm{kU} / \mathrm{l}$ and/or a positive SPT was made after an elimination diet with a food challenge. The standardized open food challenge was performed in all children $<3$ years of age and a double-blind, placebocontrolled food challenge was performed in children $>3$ years of age.

Rechallenges were performed every 6 months in the children with FA. Complete tolerance was defined as passing a challenge of whole foods and partial tolerance as no reaction to baked foods and the continuance of successful intake of these foods at home.

Statistics

Statistical analysis was performed using the Statistical Package SPSS software v17.0 (SPSS Inc., Chicago, Ill., USA). All numerical data are expressed as mean values \pm SD or as proportions.

\section{Results}

In the ADAPAR study, 33 infants with FA (to a total of 39 foods) were identified from a population of 1,377 children followed from birth. Culprit allergens established by food challenge tests included cow's milk $(n=20$, $1.4 \%)$, eggs $(n=17,1.2 \%)$, chicken meat $(n=1,0.07 \%)$ and banana $(\mathrm{n}=1,0.07 \%)$.

During the follow-up period, 28 of 33 children (84.8\%) experienced resolution of FA, with the mean age of resolution being $22.1 \pm 7.3$ months. In addition, $24.2 \%$ of the patients had an improved allergy by the age of 1 year and $51.5 \%$ by the age of 2 years. Out of 17 patients with egg allergy, 14 developed complete tolerance (82\%) and 1 developed partial tolerance. Egg allergy persisted in 2 patients at 5 years. Among 20 patients with milk allergy, complete tolerance was observed in $16(80 \%)$, partial tolerance in 1 and the allergy persisted in 3 . The mean age of tolerance to egg was $22.4 \pm 7.5$ months and to cow's milk, it was $20.9 \pm 1.1$ months. Complete tolerance to chicken meat developed at 2 years of age and to banana at 1 year of age (fig. 1). Five patients (15.1\%) had inhalantallergen sensitivity with mites and fungi being the most abundant; 1 child had walnut allergy, 1 had cocoa allergy and 3 had drug allergies.

Other allergic conditions were determined $(27.2 \%$ with allergic rhinitis, $21.2 \%$ with $\mathrm{AD}, 9 \%$ with asthma, $9 \%$ with urticaria and $9 \%$ with drug allergy) by the age of 5 years (fig. 2). A total of 16 out of 33 children (48.4\%) were diagnosed with any allergic disease.

\section{Discussion}

\section{Main Findings}

The ADAPAR study provided the first estimate of challenge-confirmed FA prevalence and prognosis in southern Turkey. The results of our study support the idea that the majority of patients with FA will eventually develop tolerance. We found that tolerance developed in 24.2, 51.5 and $84.8 \%$ of children with challenge-confirmed FA at the age of 1, 2 and 5 years, respectively. When assessed according to allergens, it was determined that $80 \%$ of the children with cow's milk allergy and $82 \%$ with egg allergy developed a tolerance by the age of 5 years.

\section{Comparison with Other Studies}

Birth cohort studies have been conducted in many countries to determine FA prognosis and different results have been reported [1]. Our study is important in terms 


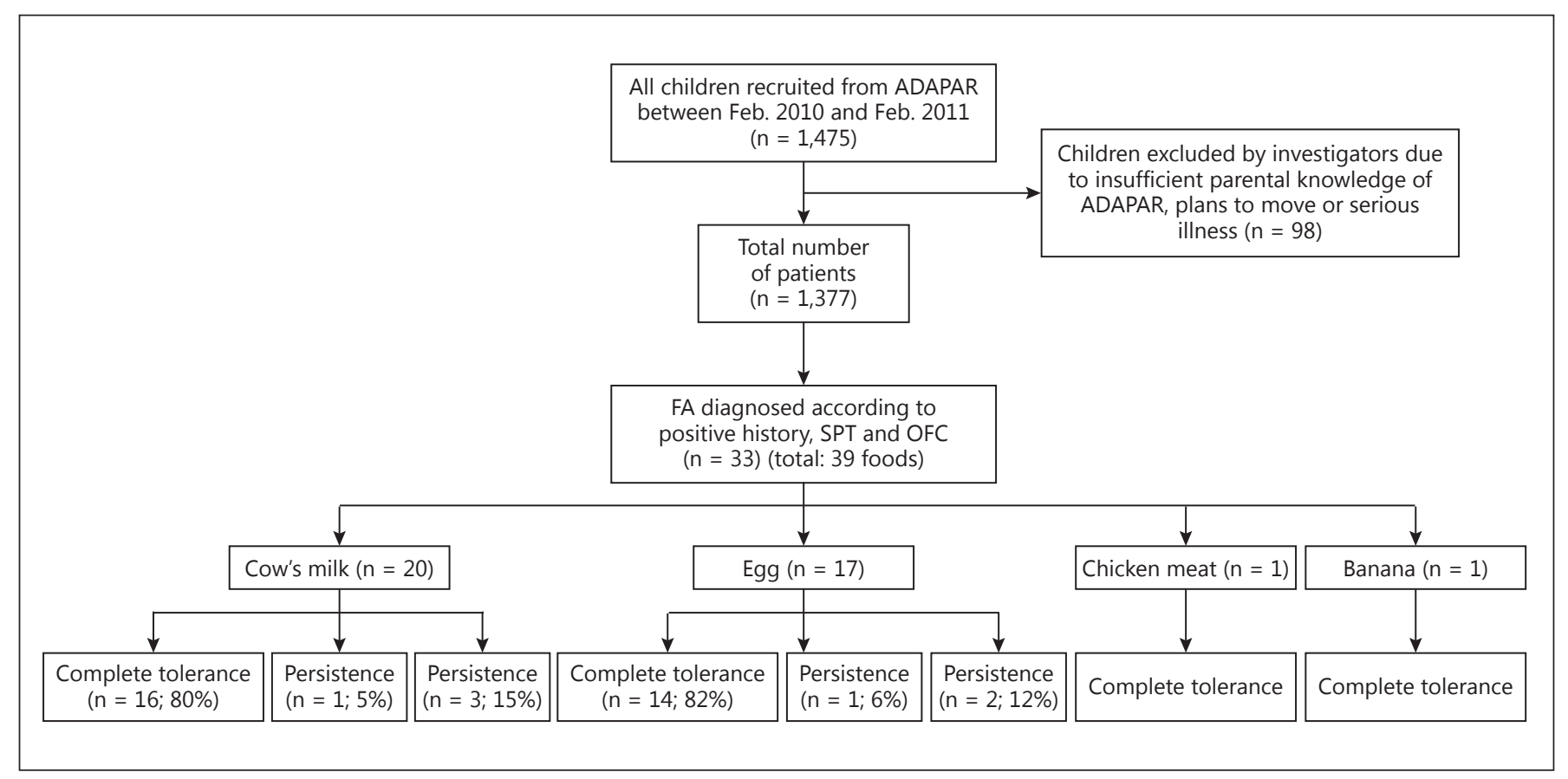

Fig. 1. An algorithm demonstrating methods of diagnosis, follow-up and rate of recovery. OFC = Oral food challenge; FA = Food allergy; SPT = skin prick test.

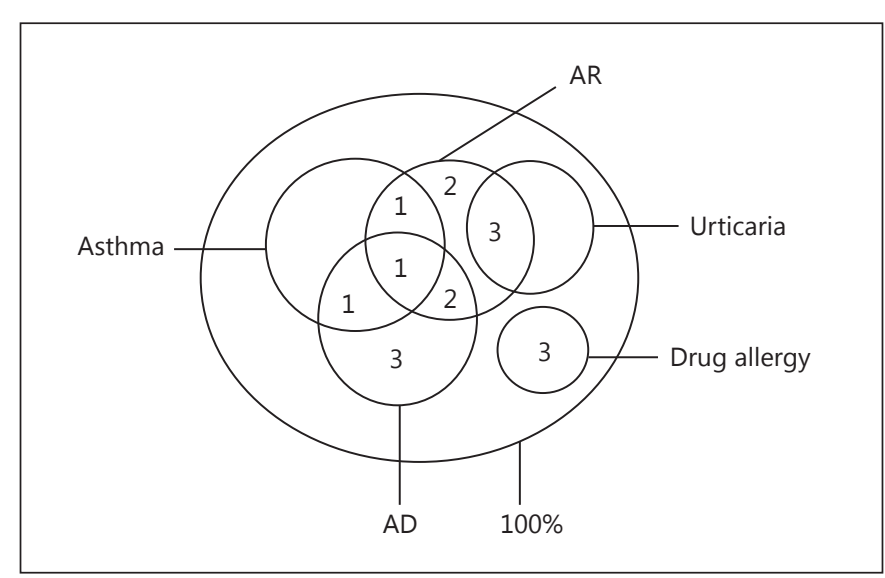

Fig. 2. Distribution of children with allergic diseases. $A R=$ Allergic rhinitis; $\mathrm{AD}=$ atopic dermatitis. Values are expressed as $\mathrm{n}$.

of showing the development of high rates of FA tolerance. In the recent EuroPrevall birth cohort studies, a lower incidence of FA (cow's milk: $0.54 \%$ and egg: $0.84 \%$ ) and higher tolerance rates (to cow's milk: 69\% and egg: $49 \%$ ) within 1 year of the initial diagnosis were reported $[2,3]$; however, challenge and follow-up rechallenge could not be applied to a significant number of children in these studies, which may account for these rates. In our study, there are several possible explanations for the high tolerance rate. The first probable explanation is that FA was detected at an early stage, perhaps even during the breastfeeding period before the infant was exposed to supplemental food; studies have shown the relationship between early exposure to supplemental food, late diagnosis and delayed tolerance in patients with FA [9]. Today, in the long-term follow-up of FA, it is known that one of the most important indicators regarding tolerance or persistence is the level of sIgE. It has been reported that at the time of diagnosis, a high level of $\operatorname{sIgE}$ and the persistence of this level was inversely related to the probability of tolerance [10]. Furthermore, meta-analyses have shown that a prolonged breastfeeding ( $>6$ months), the time point of introduction of solid foods (particularly at 4-6 months of age, 'suspected to be the critical window period'), exclusively breastfeeding for the first 4 months as well as a prebiotic and/or probiotic diet may contribute to the development of oral tolerance and could prevent some FAs and allergic diseases [11-13]. In our study, the rate of infants introduced to supplementary food at 4-6 months of age and of infants who breastfed for longer than 1 year was quite high (57.5 and $86.3 \%$, respectively, data not shown). At the same time, the rate of infants who were exclusive- 
ly breastfed for the first 4 months was considerably higher $(63.6 \%$, data not shown) than the rates generally reported in Turkey and other European countries [14]. We believe that, in our country, the first supplementary foods to which infants are introduced are rich in prebiotics (e.g. cereals, fruit and vegetables), and that this supports the high tolerance rates that we observed [15]. There is supporting evidence that probiotics reduce allergy risk with their health-promoting effects including their effects on the immune system [16]. However, in order to shed light on the course of FA and tolerance development in the long term, there is a need for studies on larger series and based on objective measurements (particularly examining the possible effects of the diet during infancy).

Another possible explanation is that early detection of FA and avoidance of allergenic foods may lead to earlier tolerance. Although the results of some studies are available, the issue of feeding practice is still controversial. Currently, management of FA is still believed to consist of avoidance of possible food allergens [13].

A number of studies have demonstrated early food sensitization to be a strong predictor of subsequent allergic diseases and sensitization to inhalants in childhood [17]. Our data demonstrate that $48.4 \%$ of children with FA at 5 years had an allergic disease and $15.1 \%$ had inhalant-allergen sensitivity. These figures are smaller than those reported elsewhere for the same age group $[18,19]$. The probable explanations of this finding are the early diagnosis of FA, the elimination of dietary allergens and the subsequent avoidance of suspected allergens.

\section{Limitations}

Our study has limitations. First, due to the small number of FA patients, our results provide limited informa- tion regarding clinical, laboratory, demographic and dietary factors that may predict the development of tolerance to certain foods. Second, the infants who did not have FA by 1 year of age in the ADAPAR study were not followed up in terms of FA which might have developed later. This factor may account for the high tolerance rates that we determined. It is well known that children who develop FA (particularly nut and peanut allergies) after infancy may have persistent FA more often than infants diagnosed with FA.

\section{Conclusion}

We presented the first birth cohort study investigating the natural history of FA from infancy to childhood in southern Turkey. FA was resolved in nearly almost all of the participants by 5 years of age. The age at the diagnosis of FA, early avoidance of the relevant food allergens, prolonged breastfeeding and dietary factors are important prognostic factors that predict the development of tolerance. Our results will help pediatricians/health staff to give more informed advice to parents of infants with cow's milk or hen's egg allergy. The clinical and laboratory relevance of these findings should be confirmed by larger prospective cohort studies.

\section{Acknowledgment}

We thank the staff of the Pediatric Allergy and Immunology Laboratory for performing the SPT and blood collection.

\section{References}

1 Wood RA: The natural history of food allergy. Pediatrics 2003;111:1631-1637.

2 Schoemaker AA, Sprikkelman AB, Grimshaw KE, Roberts G, Grabenhenrich L, Rosenfeld L, Siegert S, Dubakiene R, Rudzeviciene O, Reche M, Fiandor A, Papadopoulos NG, Malamitsi-Puchner A, Fiocchi A, Dahdah L, Sigurdardottir ST, Clausen M, StańczykPrzyłuska A, Zeman K, Mills EN, McBride D, Keil T, Beyer K: Incidence and natural history of challenge-proven cow's milk allergy in European children - EuroPrevall birth cohort. Allergy 2015;70:963-972.
3 Xepapadaki P, Fiocchi A, Grabenhenrich L, Roberts G, Grimshaw KE, Fiandor A, Ignacio Larco J, Sigurdardottir S, Clausen M, Papadopoulos LN, Dahdah L, Mackie A, Sprikkelman AB, Schoemaker AA, Dubakiene R, Butiene I, Kowalski ML, Zeman K, Gavrili S, Keil T, Beyer K: Incidence and natural history of hen's egg allergy in the first 2 years of life - the EuroPrevall birth cohort study. Allergy 2015, Epub ahead of print.

4 Nwaru BI, Hickstein L, Panesar SS, Roberts G, Muraro A, Sheikh A; EAACI Food Allergy and Anaphylaxis Guidelines Group: Prevalence of common food allergies in Europe: a systematic review and meta-analysis. Allergy 2014;69:992-1007.
5 Bousquet J, Anto J, Sunyer J, Nieuwenhuijsen M, Vrijheid M, Keil T: Pooling Birth Cohorts in Allergy and Asthma: European UnionFunded Initiatives - A MeDALL, CHICOS, ENRIECO and $\mathrm{GA}^{2} \mathrm{LEN}$ joint paper. Int Arch Allergy Immunol 2013;161:1-10.

6 Doğruel D, Bingöl G, Altıntaş DU, Yılmaz M, Kendirli SG: Prevalence of and risk factors for atopic dermatitis: a birth cohort study of infants in southeast Turkey. Allergol Immunopathol 2015, Epub ahead of print. 
7 Hohmann C, Pinart M, Tischer C, Gehring U, Heinrich J, Kull I, Melén E, Smit HA, Torrent M, Wijga AH, Wickman M, Bachert C, Lødrup Carlsen KC, Carlsen KH, Bindslev-Jensen C, Eller E, Esplugues A, Fantini MP, Annesi-Maesano I, Momas I, Porta D, Vassilaki M, Waiblinger D, Sunyer J, Antó JM, Bousquet J, Keil T; MeDALL Study Group: The development of the MeDALL core questionnaires for a harmonized follow-up assessment of eleven European birth cohorts on asthma and allergies. Int Arch Allergy Immunol 2014; 163:215-224.

8 Mangodt EA, Van Gasse AL, Decuyper I, Uyttebroek A, Faber MA, Sabato V, Bridts CH, Hagendorens MM, Ebo DG: In vitro diagnosis of immediate drug hypersensitivity: should we go with the flow? Int Arch Allergy Immunol 2015;168:3-12.

9 Savage J, Johns CB: Food allergy: epidemiology and natural history. Immunol Allergy Clin North Am 2015;35:45-59.
10 Peters RL, Gurrin LC, Dharmage SC, Koplin JJ, Allen KJ: The natural history of IgE-mediated food allergy: can skin prick tests and serum-specific IgE predict the resolution of food allergy? Int J Environ Res Public Health 2013;10:5039-5061.

11 Szajewska H: Understanding the role of probiotics and prebiotics in preventing allergic disease: evidence and methodological issues. Immunotherapy 2013;5:869-878.

12 Kuitunen M: Probiotics and prebiotics in preventing food allergy and eczema. Curr Opin Allergy Clin Immunol 2013;13:280-286.

13 Longo G, Berti I, Burks AW, Krauss B, Barbi E: IgE-mediated food allergy in children. Lancet 2013;382:1656-1664.

14 Özlüses E, Celebioglu A: Educating fathers to improve breastfeeding rates and paternal-infant attachment. Indian Pediatr 2014;51:654657.
15 Prescott SL, Pawankar R, Allen KJ, Campbell DE, Sinn JKh, Fiocchi A, Ebisawa M, Sampson HA, Beyer K, Lee BW: A global survey of changing patterns of food allergy burden in children. World Allergy Organ J 2013;6:21.

16 Prescott S, Nowak-Wegrzyn A: Strategies to prevent or reduce allergic disease. Ann Nutr Metab 2011;59:28-42.

17 Bihouée T, Bouchaud G, Chesné J, Lair D, Rolland-Debord C, Braza F, Cheminant MA, Aubert P, Mahay G, Sagan C, Neunlist M, Brouard S, Bodinier M, Magnan A: Food allergy enhances allergic asthma in mice. Respir Res 2014; $15: 142$.

18 Kjaer HF, Eller E, Andersen KE, Høst A, Bindslev-Jensen C: The association between early sensitization patterns and subsequent allergic disease. The DARC birth cohort study. Pediatr Allergy Immunol 2009;20:726734

19 Tariq SM, Matthews SM, Hakim EA, Arshad SH: Egg allergy in infancy predicts respiratory allergic disease by 4 years of age. Pediatr Allergy Immunol 2000;11:162-167. 